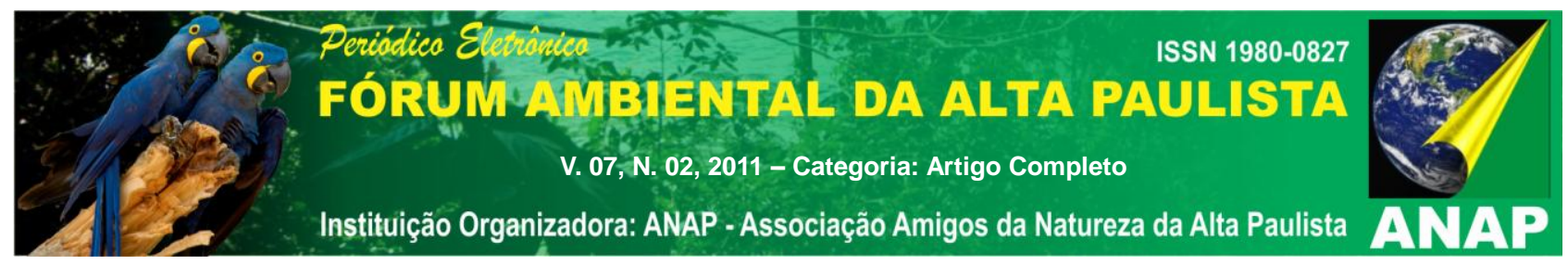

\title{
ESTUDO DO SUB-BACIA HIDROGRÁFICA DO RIO MONJOLINHO, SÃO CARLOS - SP, UTILIZANDO O MODELO MATEMÁTICO DE QUALIDADE DA ÁGUA QUAL-2E.
}

\section{Gabriela Rahal de Rezende ${ }^{1}$}

RESUMO: Os modelos de qualidade da água são uma importante ferramenta para o manejo das Bacias Hidrográficas, por conseguirem integrar uma série de informações ambientais, possibilitando assim uma visão dinâmica dos processos naturais. Com a modelagem matemática é possível ainda realizar simulações de cenários futuros, que podem colaborar com o processo de tomada de decisão.

O programa QUAL-2E, na sua interface QUAL-2R, é uma destas valiosas ferramentas, possibilitando a simulação de curso d' água unidirecional, bem misturado e de fluxo constante. O presente trabalho propõe avaliar a aplicação do modelo QUAL-2E para simulações das concentrações de nitrogênio e fósforo no rio Monjolinho, São Carlos (SP).

Foi realizada a calibração do modelo e determinados os coeficientes de autodepuração para os parâmetros: nitrogênio amoniacal, nitrato, nitrito e fosfato. Posteriormente o modelo foi validado apresentando resultados satisfatórios em relação aos dados coletados no campo. Em seguida, propôs-se a simulação da qualidade da água do rio Monjolinho após a implementação da estação de tratamento esgoto de São Carlos. Os resultados demonstraram que o rio poderá sofrer alterações em sua qualidade, mesmo que os efluentes da estação estejam dentro dos padrões de emissão estabelecidos pelo CONAMA (Conselho Nacional de Meio Ambiente), dadas as particularidades do Monjolinho.

Palavras-chave: Modelação matemática. QUAL2E. Gestão de recursos hídricos

\footnotetext{
${ }^{1}$ Engenheira Ambiental, Escola de Engenharia de São Carlos, USP-SP. gabrielarahal@gmail.com
} 


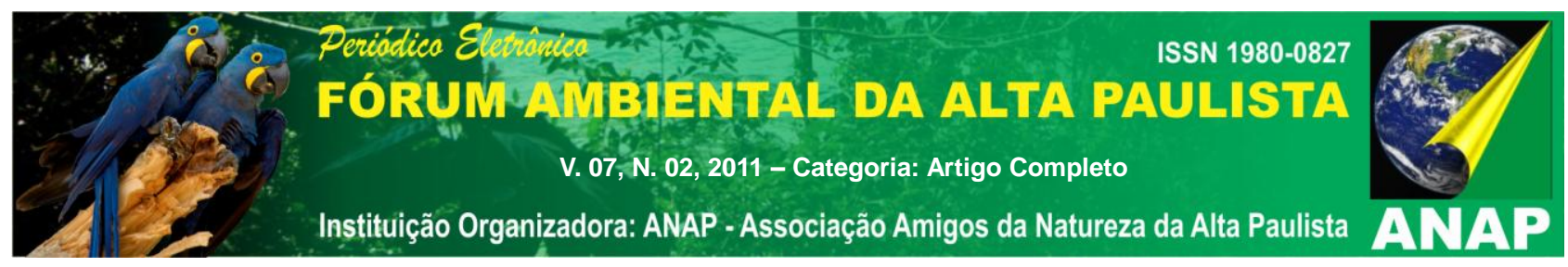

\section{INTRODUÇÃO}

A gestão dos recursos hídricos é complexa, já que o controle da qualidade da água está associado a uma visão holística, no nível de toda bacia hidrográfica, e não apenas pelo agente alterador (VON SPERLING, 2005), sendo necessária a utilização de ferramentas tecnológicas e instrumentos políticos para antever os potenciais impactos e solucionar problemas causados pelos conflitos do uso da água.

Os modelos matemáticos de qualidade da água são técnicas que possibilitam simular condições reais, dentro de uma faixa de incertezas, permitindo a apresentação de propostas e alternativas para gerenciamento dos recursos naturais (TUCCI, 1998). Apesar das muitas limitações e incertezas que rondam os modelos matemáticos, muitos pesquisadores os têm utilizado na modelagem de sistemas ambientais, uma vez que os diversos ciclos (principalmente de nutrientes) que ocorrem na natureza apresentam alta complexidade, o que torna praticamente impossível, para o ser humano, unir e entender uma série de informações e dados desconexos, sem a ajuda de programas computacionais.

\section{$1.1 \underline{\text { Objetivo }}$}

Este trabalho teve como objetivo pesquisar e avaliar a qualidade da água do rio Monjolinho, localizado no município de São Carlos, no Estado de São Paulo, usando o modelo matemático de qualidade da água QUAL-2E, através do estudo das interações do nitrogênio em suas diversas formas amoniacal, nitrito, nitrato e da concentração de fósforo. Além desse objetivo geral, teve-se como meta, também, a calibração e a validação do modelo QUAL-2E, por meio de consulta a informações existentes e coletas de campo na sub-bacia em questão.

Este projeto visou também realizar a simulação de condições futuras do rio Monjolinho, para demonstrar a aplicação dos modelos matemáticos de qualidade da água no gerenciamento dos recursos hídricos.

\subsection{Aspectos qualitativos da água}

O conceito de qualidade vai além de caracterizar a água simplesmente pela sua fórmula $\mathrm{H}_{2} \mathrm{O}$. Isso porque a água incorpora a si diversas impurezas, devido às suas 


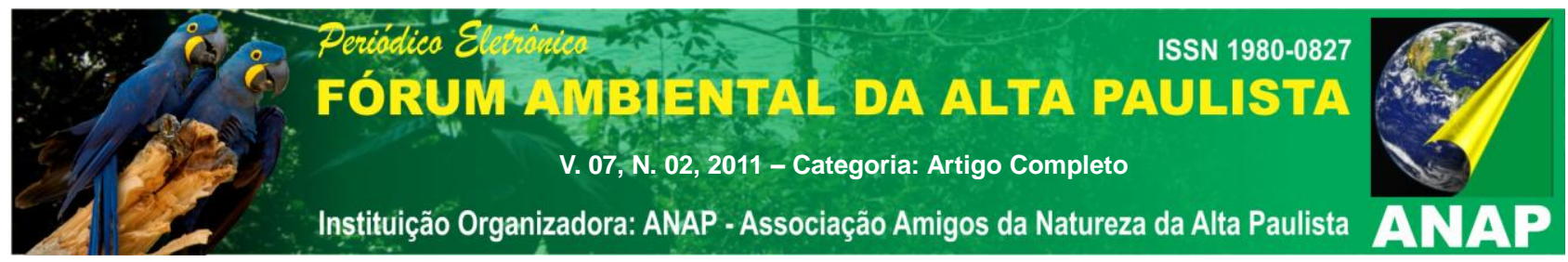

propriedades de solvente e à sua capacidade de transportar partículas, as quais definem a qualidade da água.

A qualidade da água é função das características geológicas e geomorfológicas, da cobertura vegetal, e principalmente, do uso e ocupação do solo da bacia hidrográfica. Esse último tema é muito importante por retratar as pressões e impactos das atividades humanas sobre o recurso natural.

A interferência antrópica nos recursos hídricos pode ocorrer tanto de forma pontual, com a geração e despejo de efluentes domésticos e industriais nos corpos d'água, quanto de forma dispersa, como na aplicação de defensivos agrícolas e fertilizantes no solo, poluição industrial, chuva ácida, entre outras.

É difícil estabelecer, na prática, uma análise sistemática de todos os poluentes que possam estar presentes nos mananciais superficiais. Dessa maneira os órgãos ambientais pré-definiram alguns indicadores físicos, químicos e biológicos que, analisados em conjunto, possibilitam verificar os níveis de poluição de um determinado manancial.

Os parâmetros de qualidade da água são de fundamental importância para a modelação matemática de um corpo d'água, já que eles serão os dados utilizados na calibração e na validação do modelo. Podemos citar os seguintes parâmetros como sendo fundamentais para os estudos de qualidade da água: potencial hidrogeniônico, temperatura d'água, sólidos totais e dissolvidos, demanda bioquímica de oxigênio, organismos patogênicos, nitrogênio orgânico, nitrogênio amoniacal, nitrito, nitrato, fósforo orgânico, fósforo inorgânico, metais pesados.

\subsection{Desenvolvimento de um Modelo Matemático de Qualidade da Água}

Segundo Loucks (1981), para o desenvolvimento matemático de qualidade da água faz-se necessário percorrer diversas etapas até que este possa ser utilizado como uma ferramenta efetiva no gerenciamento dos recursos hídricos.

A primeira fase, Fase de Calibração, baseia-se no conjunto de informações de entradas e saídas observadas no curso de água pois a partir disto, serão determinados os coeficientes, como o de desoxigenação e aeração. Esta fase se faz necessária para melhor representação da situação real (LOUCKS, 1981). 


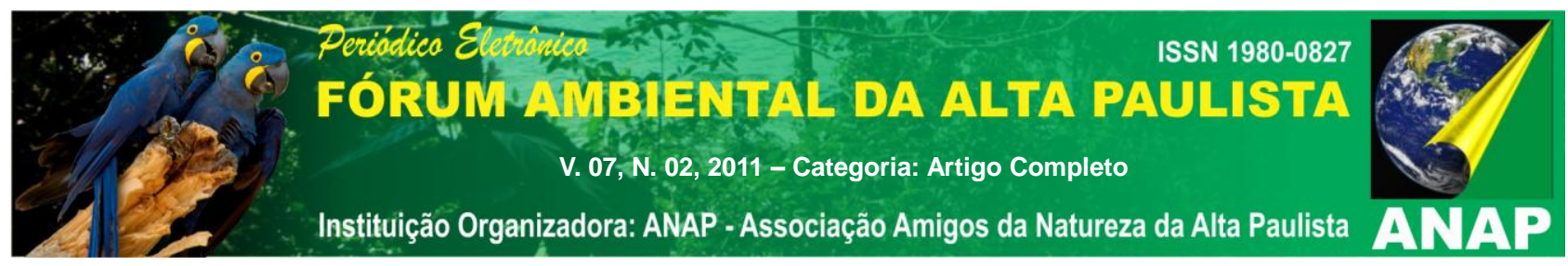

A calibração pode ser considerada como um procedimento primordial para a utilização de um modelo matemático. Esse processo possibilita ao usuário determinar os coeficientes das equações matemáticas utilizadas na modelação dos processos físicos, químicos e biológicos que ocorrem no curso d' água, a fim de se obter uma simulação com precisão satisfatória das características reais do rio (OPPA, 2007).

$\mathrm{Na}$ segunda fase, todo o equacionamento do modelo é testado, verificando-se a consistência entre as equações matemáticas utilizadas e a dinâmica real dos mecanismos (LOUCKS, 1981).

$\mathrm{Na}$ última etapa, Fase de Simulação, o modelo de qualidade da água deverá estar apto a reproduzir casos diferentes envolvendo condições adversas (LOUCKS, 1981).

Após estas etapas, o modelo desenvolvido deverá ser capaz de proporcionar uma melhor gestão dos recursos hídricos de uma bacia já que este estará adaptado para as necessidades do usuário.

\subsection{Modelo QUAL- 2E}

Em 1985, a Southeast Michigan Council of Governments (SEMCOG) lançou o QUAL2E, um modelo versátil para qualidade de águas correntes que permite a simulação de até quinze parâmetros, são eles: demanda bioquímica de oxigênio (demanda carbonácea), oxigênio dissolvido, demanda bentônica de oxigênio, clorofila, nitrogênio (amônia, nitrito e nitrato), fósforo, coliformes, material radioativo, minerais conservativos, temperatura (PALMIERI, 2004).

O modelo QUAL2E apresenta certas limitações dimensionais referentes ao número de trechos (máximo quinze) e elementos computacionais (máximo quinhentos). Outra limitação do QUAL2E é que este apenas simula condições onde o fluxo e as descargas de efluentes na bacia são constantes. Apesar destes problemas o modelo é amplamente utilizado em todo o mundo, havendo diversos exemplos de aplicação no Brasil (PALMIERI, 2004 e RONDON LIMA, 2001).

\section{$1.6 \underline{\text { Usos Múltiplos }}$}

Até a década de 50, de acordo com a menor demanda pelos recursos hídricos, os conflitos pelo o uso da água não eram muito evidenciados, e pouco se discutia 


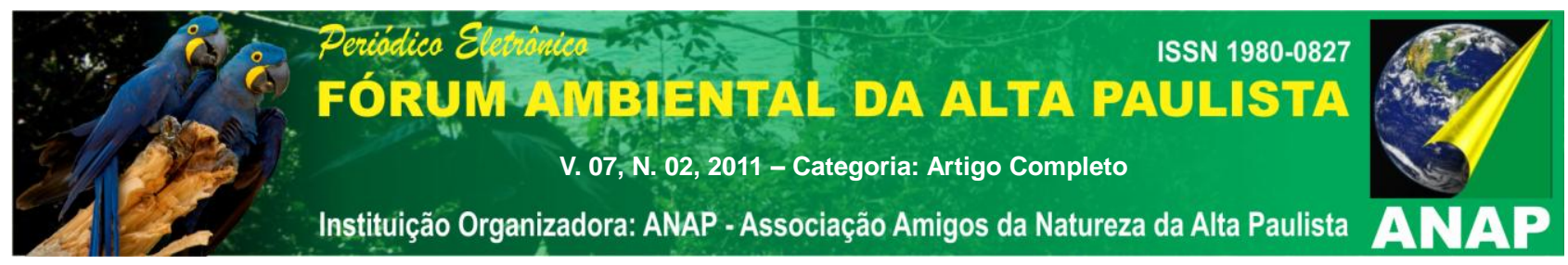

sobre o assunto. Hoje a situação é diferente, com o aumento populacional e industrial sendo que, em alguns países, a oferta de água se encontra menor que a demanda.

Em uma análise geral sobre esse problema o Plano Nacional de Saneamento constata que grande parte do comprometimento da qualidade da água para abastecimento público é decorrente do lançamento de efluentes, sobretudo domésticos, ficando evidente a demanda por integrar a gestão dos recursos hídricos ao planejamento.

Com a finalidade de evitar possíveis conflitos e de proporcionar um gerenciamento mais democrático das águas do Brasil, a Lei 9.433/1997 - Política Nacional de Recursos Hídricos, estabeleceu que a gestão d'água deve proporcionar o seu uso múltiplo. Entende-se por uso múltiplo o ato de conciliar as diversas atividades humanas relacionadas aos recursos hídricos, de tal forma que as mesmas possam coexistir de maneira harmônica e principalmente, sem que o meio ambiente venha a ser prejudicado em detrimento de outros usos.

Porém, o compartilhamento dos recursos hídricos por diversos usuários e setores da sociedade civil exige o estabelecimento de complexas regras operacionais. As decisões devem ser tomadas em conjunto pelo governo e pela sociedade, uma vez que onde há interesses distintos não é simples a mediação de possíveis conflitos.

O país encontra-se na fase inicial de implementação do processo dos usos múltiplos, uma vez que a legislação na área é recente, mas alguns avanços podem ser notados como a criação, no Estado de São Paulo, de 22 Unidades de Gerenciamento de Recursos Hídricos - UGRHIs e os respectivos comitês de bacia hidrográfica.

\section{DESENVOLVIMENTO}

O rio Monjolinho integrado à Bacia Hidrográfica do rio Jacaré-Guaçu, um dos principais afluentes do rio Tietê, tem um área de drenagem de $274 \mathrm{Km}^{2}$ e se encontra quase totalmente em São Carlos (SP). Município este que tem a economia fundamentada em atividades industriais e agropecuárias.

Segundo Sé (1992) a demanda por água para as atividades urbanas passou por grandes transformações após a década de 50 e 60. Com o desenvolvimento industrial e a urbanização, a demanda pela água, tanto quantitativa como qualitativamente, aumentou, 


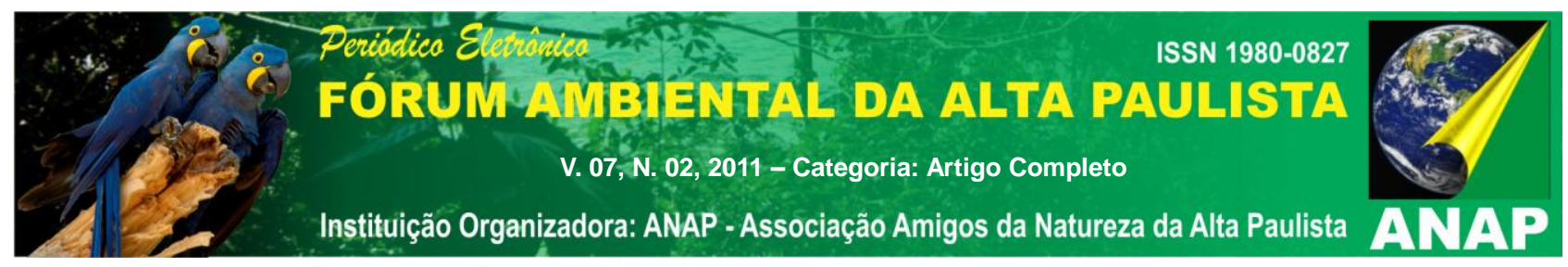

diversificando-se os usos e abrindo a necessidade de captação em outras bacias hidrográficas para atender a cidade de São Carlos.

Pode-se observar na Figura 1 que o desenvolvimento urbano da cidade se fez dentro dos limites geográficos da bacia hidrográfica.

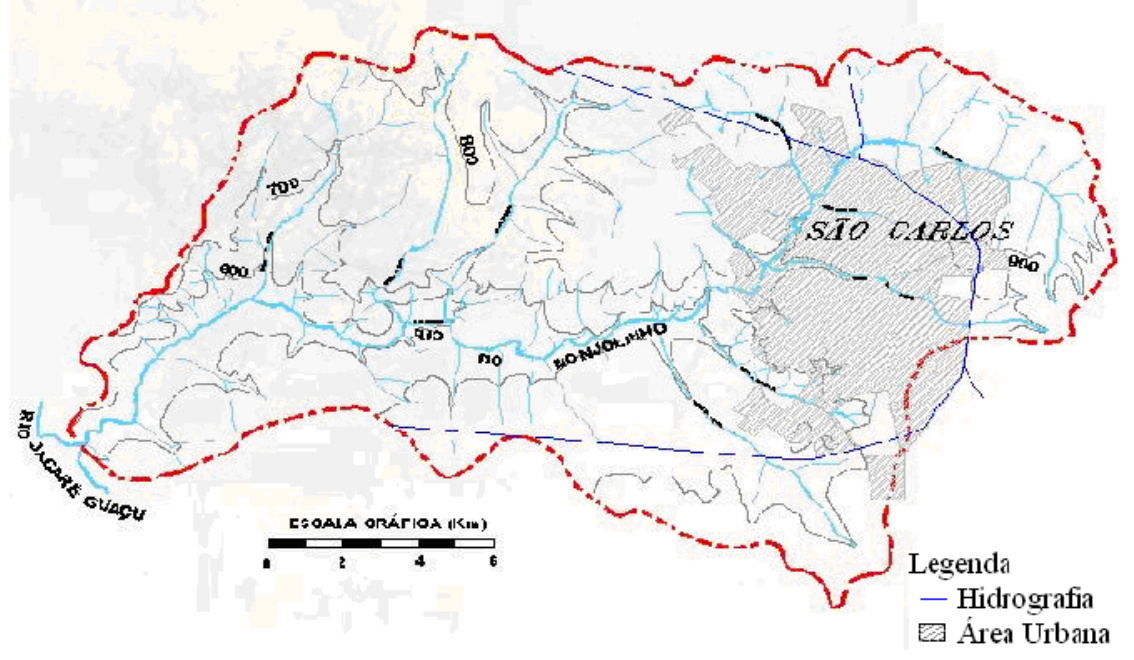

Figura 1 - Bacia hidrográfica do rio Monjolinho

$\mathrm{Na}$ área urbanizada o rio Monjolinho recebe grandes contribuições de águas residuárias, incluindo o esgoto sanitário da cidade de São Carlos e efluentes industriais (curtumes, papel, tinta, matadouros, alimentos entre outros). Estes chegam ao corpo d' água através do lançamento em seus afluentes que são: o Tijuco Preto, o córrego do Gregório e o Santa Maria Madalena. (BARRETO, 1999)

\subsection{Materiais e métodos}

Nesta etapa do estudo será descrito qual foi a metodologia do trabalho.

\subsubsection{Calibração do Modelo QUAL-2R}

Foi utilizada a interface do modelo QUAL-2E, QUAL 2R, que se mostrou mais simples e compatível com os sistemas operacionais utilizados.

A fase de calibração consistiu em adaptar o modelo QUAL $2 R$ às condições específicas do rio Monjolinho. Foram realizados testes com o intuito de escolher os valores de coeficientes matemáticos que trouxessem um resultado mais próximo com a realidade. 


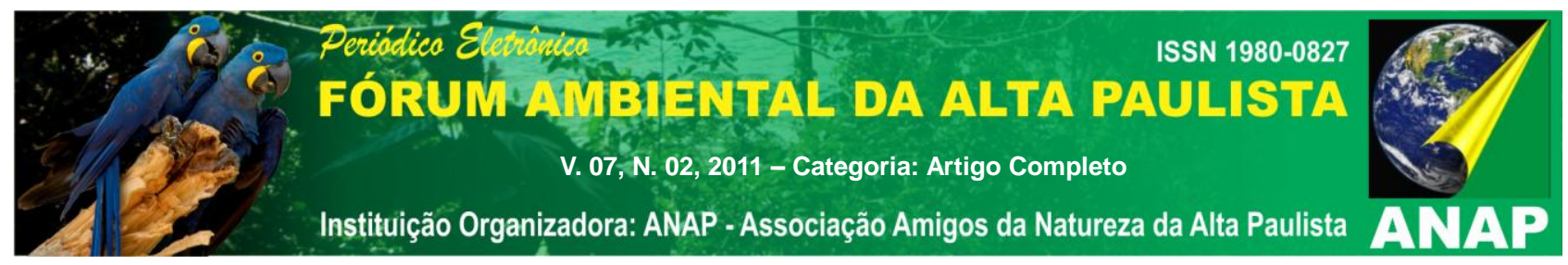

\subsubsection{Validação do modelo QUAL-2E}

A validação é considerada um processo extremamente importante, pois comprova que os modelos são capazes de reproduzir através de expressões matemáticas os processos físicos, químicos e biológicos que ocorrem no interior de uma bacia hidrográfica.

Para a realização da calibração do modelo QUAL-2E, foi feita uma coleta de dados no dia 08 de julho de 2008 no rio Monjolinho. Com isso, a veracidade das informações geradas pelo modelo foi testada através da comparação entre os dados coletados e os obtidos pela modelação.

\subsection{Resultados e Discussão} tópicos.

Os resultados e a discussão do trabalho podem ser analisados nos seguintes

\subsubsection{Calibração}

Para a simulação da qualidade da água foram utilizados os $44 \mathrm{~km}$ de extensão do rio Monjolinho, ou seja, da nascente até sua foz no rio Jacaré-Guaçu. O sistema fluvial foi dividido em seis trechos, de acordo com os limites do modelo e considerando as características hidrológicas do corpo d'água estudado. Cada um dos 44 elementos computacionais tem comprimento de $1 \mathrm{~km}$.

Os dados climatológicos e geográficos utilizados no modelo foram escolhidos com base nas indicações na tese de Barreto (1999) e nas experiências obtidas por Rodrigues (2005).

Foi utilizado para a calibração do modelo, o valor de 60 (sessenta) para a constante de dispersão longitudinal, que é o valor recomendado como padrão pelo manual do QUAL-2E.

O valor adotado do coeficiente de rugosidade de Manning foi igual a $0,035 \mathrm{e}$ constante em todos os trechos do sistema fluvial simulado, pois este valor é o mais utilizado para cursos d'água rasos e com remanso, que é o caso do rio Monjolinho. Esta consideração foi baseada em Mccutcheon (1989) apud Lima (1999). 


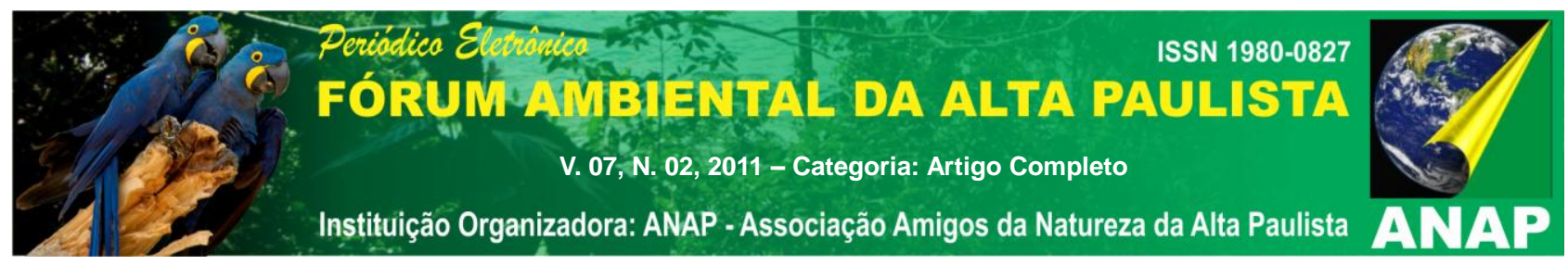

Os demais coeficientes hidráulicos requeridos pelo modelo foram obtidos através de outros trabalhos, como Barretto (1999) que aferiu dados de velocidade, vazão e geometria do canal do rio Monjolinho em pontos iguais ao utilizado neste trabalho.

A condição inicial de cada trecho está na tabela a seguir. Esses dados foram utilizados como base para as simulações de autodepuração do corpo d'água e para comparação com os dados gerados pelo modelo na calibração.

Tabela 1 - Valores dos parâmetros iniciais de cada trecho

\begin{tabular}{cccccccc}
\hline Trecho & $\begin{array}{c}\text { Temperatura } \\
\left(\mathbf{C}^{\circ}\right)\end{array}$ & $\begin{array}{c}\mathbf{N}- \\
\text { Orgânico } \\
(\mathbf{m g} / \mathbf{L})\end{array}$ & $\begin{array}{c}\mathbf{N}- \\
\text { Amoniacal } \\
(\mathbf{m g} / \mathbf{L})\end{array}$ & $\begin{array}{c}\text { Nitrito } \\
(\mathbf{m g} / \mathbf{L})\end{array}$ & $\begin{array}{c}\text { Nitrato } \\
(\mathbf{m g} / \mathbf{L})\end{array}$ & $\begin{array}{c}\mathbf{P}- \\
\text { Orgânico } \\
(\mathbf{m g} / \mathbf{L})\end{array}$ & $\begin{array}{c}\mathbf{P}- \\
\text { Dissolvido } \\
(\mathbf{m g} / \mathbf{L})\end{array}$ \\
\hline 1 & 20 & 2,32 & 0,86 & 0,015 & 1,16 & 0,083 & 0,03 \\
2 & 22 & 7,30 & 1,76 & 0,012 & 1,00 & 0,188 & 0,10 \\
3 & 23 & 6,40 & 2,48 & 0,045 & 1,71 & 0,448 & 0,12 \\
4 & 24 & 11,20 & 1,95 & 0,055 & 1,63 & 0,409 & 0,11 \\
5 & 25 & 10,90 & 4,30 & 0,035 & 1,70 & 1,450 & 0,77 \\
6 & 24 & 8,80 & 3,20 & 0,050 & 1,30 & 1,000 & 0,16 \\
\hline
\end{tabular}

Fonte: Barreto, 2005

Os coeficientes para a calibração do nitrogênio e do fósforo foram determinados utilizando como base uma faixa de valores fornecida por Fagundes (2006). Dentro desta faixa, realizaram-se três simulações sendo que em cada uma delas foram determinados valores de coeficiente diferentes, com o objetivo de escolher quais destas faixas de valores geravam situações mais próximas dos dados coletados. Os resultados obtidos podem ser analisados nos gráficos seguintes que apresentam os dados observados na campanha de Barreto (2005) e a simulação realizada pelo modelo QUAL2E para os parâmetros escolhidos com três diferentes faixas de valores de coeficiente. 

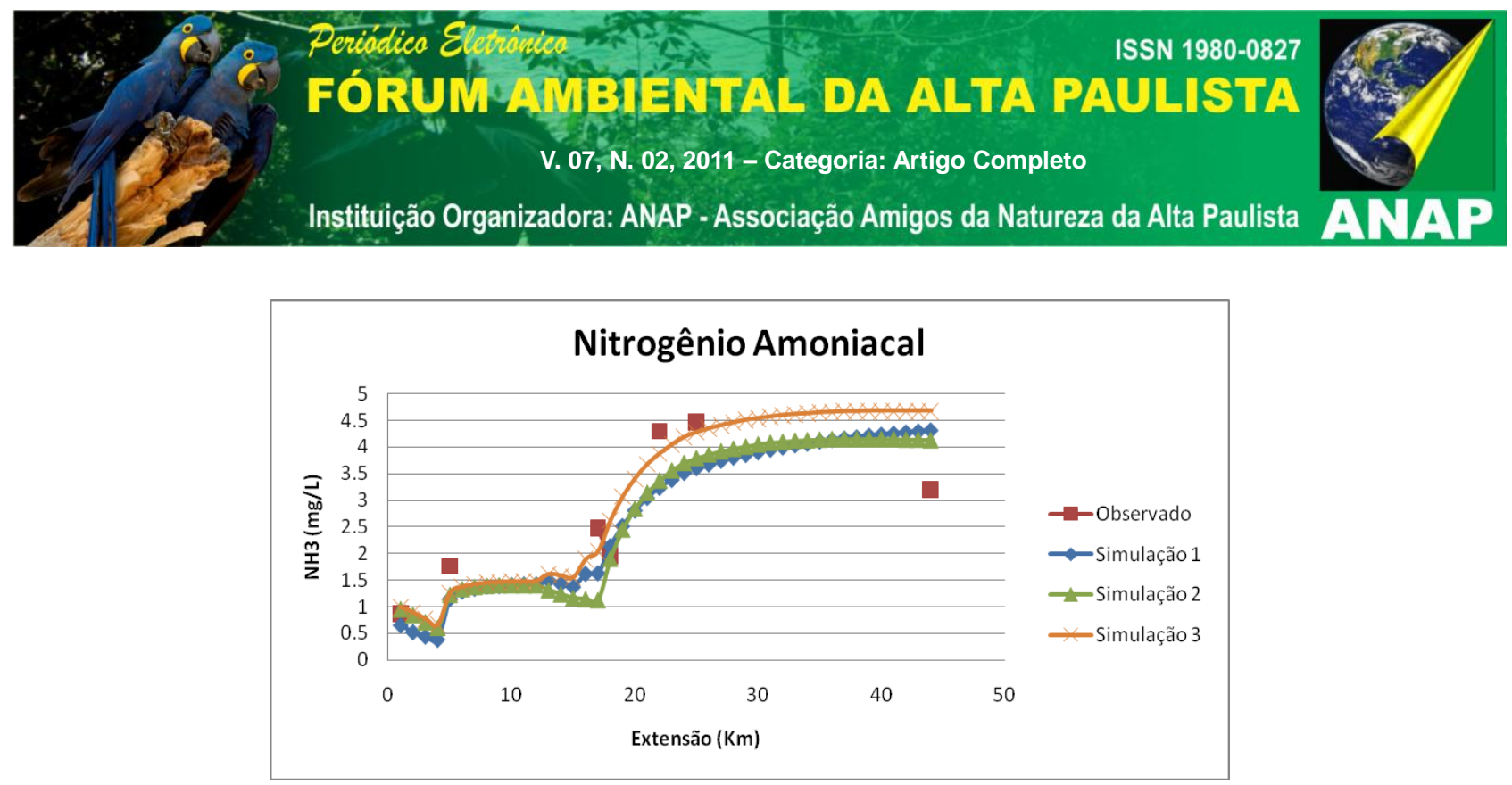

Figura 2 - Calibração do modelo QUAL-2E: comportamento da concentração de nitrogênio amoniacal no rio Monjolinho

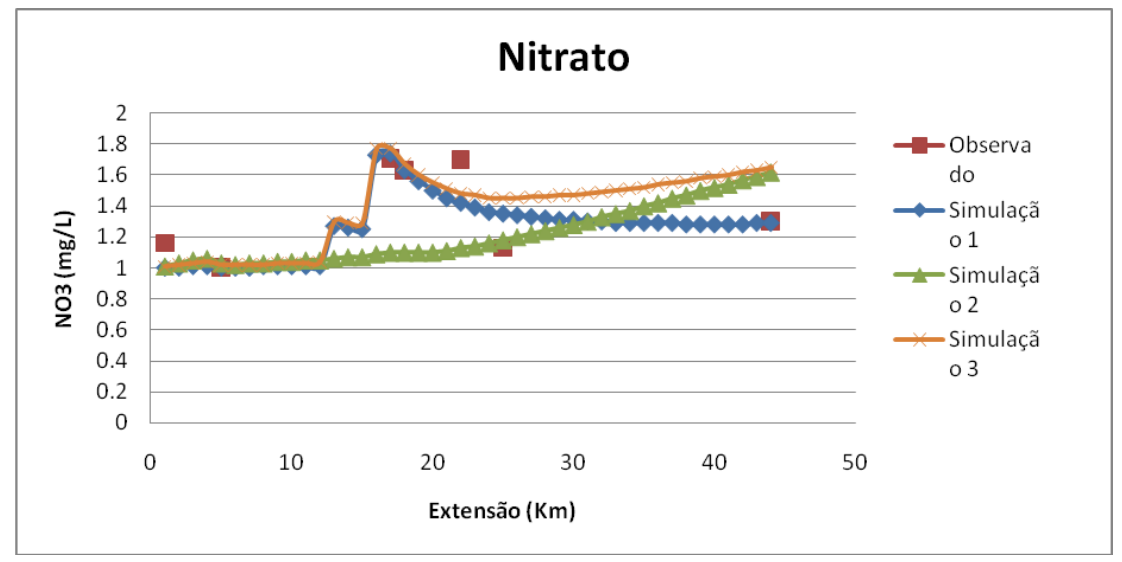

Figura 3 - Calibração do modelo QUAL-2E: comportamento da concentração de nitrato no rio Monjolinho

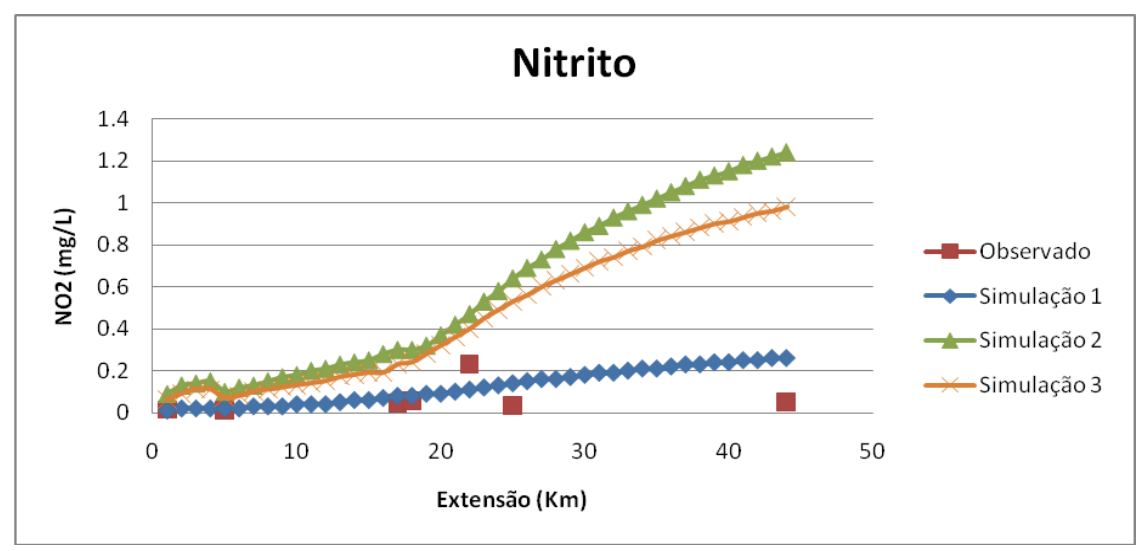

Figura 4 - Calibração do modelo QUAL-2E: comportamento da concentração de nitrito no rio Monjolinho 

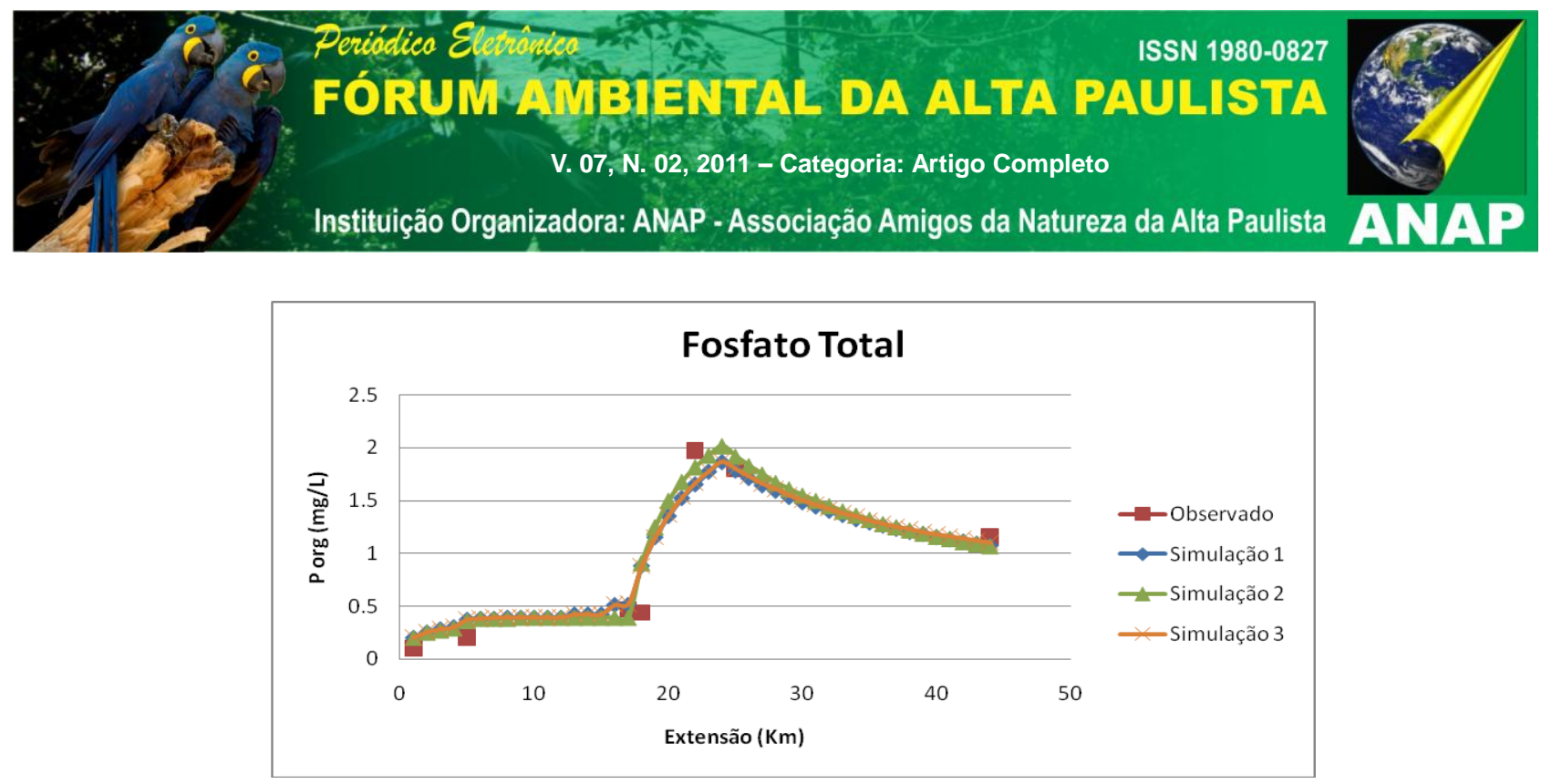

Figura 5 - Calibração do modelo QUAL-2E: comportamento da concentração de fosfato total no rio Monjolinho

Pode-se observar que para a calibração do nitrogênio amoniacal e nitrato, as simulações 1 e 3 se aproximam do padrão apresentado pelos valores observados (figura 2 e 3). No entanto, na simulação de nitrito, a única simulação que se mostra aproximada é a 1 (figura 4), provavelmente pelo valor do coeficiente de hidrólise do $\mathrm{N}$-orgânico.

Para a simulação do fosfato total pode-se analisar que não ocorreram grandes alterações no padrão das diferentes simulações (figura 5), sendo assim adotaram-se os valores dos coeficientes obtidos na simulação 1 para realizar a validação do modelo, já que essa simulação apresentou os valores mais próximos do observado tanto para a calibração do nitrogênio quanto do fósforo.

A calibração foi o processo mais complexo do estudo por abranger a manipulação de um grande número de dados e pela dificuldade em se encontrar os valores dos coeficientes na bibliografia. Pode-se considerar também que ocorreram alterações no curso d'água no intervalo de tempo entre este estudo e os da bibliografia. Esses fatores podem ter gerado algumas diferenças entre os valores observados e os simulados. Apesar disso considera-se que a calibração cumpriu seu objetivo em adaptar o modelo ao rio Monjolinho.

\subsubsection{Validação do modelo QUAL-2E}

O processo de validação é realizado nos modelos matemáticos de qualidade da água para comprovar se os coeficientes adotados na etapa anterior apresentam uma precisão satisfatória.

Para a validação do modelo QUAL-2E para a bacia hidrográfica do rio Monjolinho foram utilizados os dados qualitativos e quantitativos coletados na campanha a campo de 08 de julho de 2008, realizada especificamente para este trabalho. Na tabela 11, encontram-se os valores de nitrogênio amoniacal, nitrito, nitrato e fósforo total observado nesta campanha. 


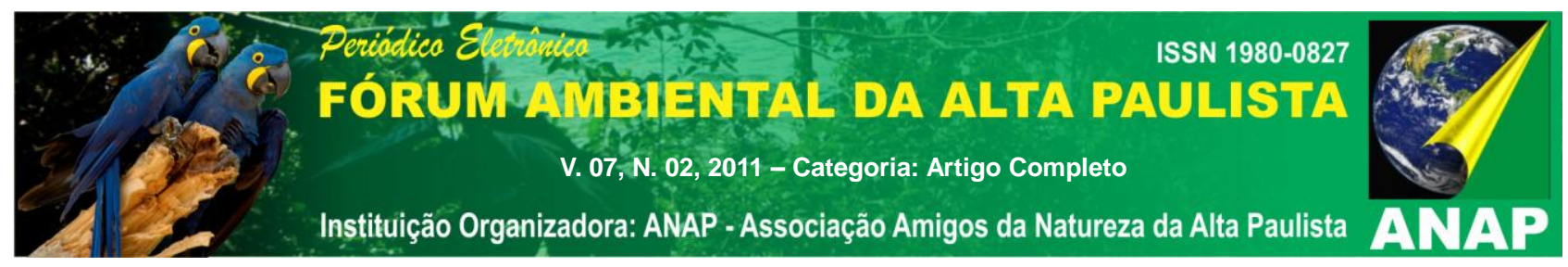

Tabela 2 - Parâmetros analisados na coleta dia 08/07/08 no rio Monjolinho

\begin{tabular}{cccccc}
\hline Trechos & $\begin{array}{c}\text { Quilometragem a } \\
\text { partir da nascente }\end{array}$ & $\begin{array}{c}\text { Amônia } \\
(\mathbf{m g} / \mathbf{L})\end{array}$ & $\begin{array}{c}\text { Nitrito } \\
(\mathbf{m g} / \mathbf{L})\end{array}$ & Nitrato $\mathbf{( m g} / \mathbf{L})$ & $\begin{array}{c}\text { Fosfato } \\
(\mathbf{m g} / \mathbf{L})\end{array}$ \\
\hline 1 & 1 & 0,11 & 0,0029 & 0,9255 & 0,0327 \\
2 & 5 & 0,05 & 0,0019 & 0,4272 & 0,0222 \\
3 & 13 & 0,26 & 0,0150 & 0,4433 & 0,0633 \\
4 & 16 & 0,24 & 0,0579 & 1,1425 & 0,1468 \\
5 & 25 & 10,00 & 0,0079 & 0,1600 & 1,4496 \\
6 & 44 & 5,00 & 0,0367 & 0,2600 & 0,5084 \\
\hline
\end{tabular}

Durante a simulação do modelo Qual2E foram considerados dois pontos de lançamento pontual, que correspondem ao córrego do Tijuco Preto e ao córrego do Gregório, no inicio dos trechos 3 e 4 respectivamente. Os valores de nitrogênio e fósforo desses corpos d'água constam na tabela a seguir.

Tabela 3 - Parâmetros analisados na coleta do dia 08/07/08 nos afluentes do Monjolinho

\begin{tabular}{ccccc}
\hline Pontos de coleta & Amônia (mg/L) & Nitrito $(\mathbf{m g} / \mathbf{L})$ & Nitrato $(\mathbf{m g} / \mathbf{L})$ & Fosfato $(\mathbf{m g} / \mathbf{L})$ \\
\hline Córrego Tijuco Preto & 0,17 & 0,0974 & 5,1932 & 0,0898 \\
Córrego Gregório & 0,35 & 0,0967 & 0,9668 & 0,1580 \\
\hline
\end{tabular}

Os coeficientes hidráulicos, cinéticos e os dados climatológicos foram os mesmos utilizados na calibração - Simulação 1. A Figura a seguir mostra o perfil da simulação da concentração de fosfato total fornecidas pelo modelo QUAL2E e os valores da coleta do dia 8 de julho de 2008, afim de comparação.

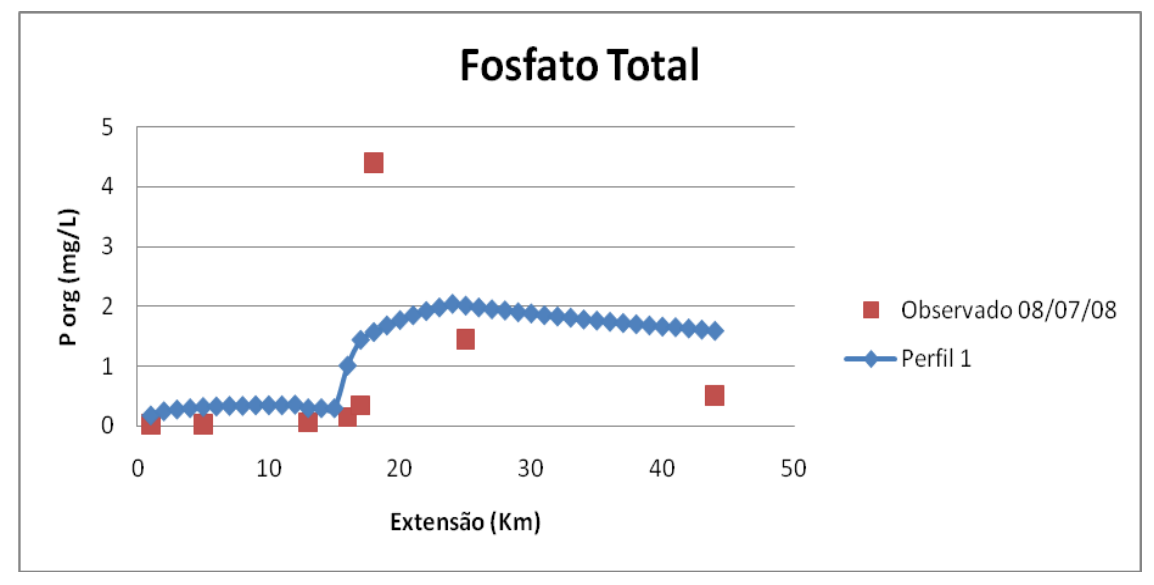

Figura 6 - Validação - perfil simulado pelo modelo Qual2E da concentração de nitrogênio fosfato total no rio Monjolinho e os dados observados na campanha.

As concentrações de fosfato têm um crescimento exponencial após o início do trecho 3 (três) onde o Monjolinho começa a receber vários afluentes. Esse parâmetro ultrapassa o limite da resolução CONAMA 357 de 2005, que estabelece o limite de $0,1 \mathrm{mg} / \mathrm{L}$ de fósforo para ambientes lóticos. 


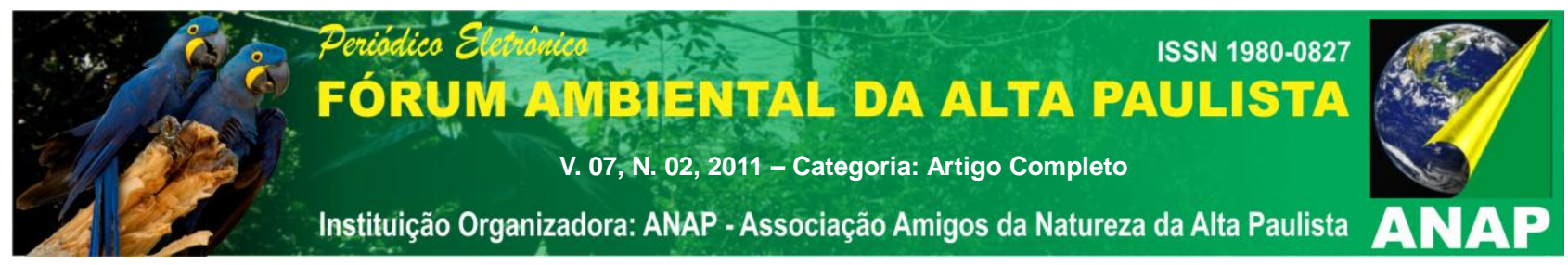

Esta figura e as outras relacionadas à validação dos parâmetros do nitrogênio mostraram que o modelo QUAL-2R se ajustou com uma precisão satisfatória em relação aos dados amostrais coletados no rio Monjolinho. Apesar de que no gráfico apresentado existe um pico que extrapola o perfil. Isso se deve possivelmente a cargas pontuais recentes que não foram identificadas na calibração do modelo, principalmente devido à descarga pontual de esgoto sanitário que ocorre após o trecho 5 , no rio Monjolinho.

\subsubsection{Simulação da implantação da ETE - São Carlos}

Em 2005, o governo municipal de São Carlos, na figura do Serviço Autônomo de Água e Esgoto (SAAE), juntamente com o Comitê de Bacia do rio Jacaré Guaçu e com os órgãos responsáveis pelo gerenciamento dos recursos hídricos no âmbito federal e estadual deram início às obras da construção da estação de tratamento de esgoto Monjolinho, ETE-Monjolinho.

Desta forma, utilizou-se o modelo QUAL-2E calibrado e validado para realizar um prognóstico das condições do rio Monjolinho após a implementação da Estação de Tratamento de Esgoto do Monjolinho, quanto à concentração de nitrogênio no sistema fluvial.

Com esse intuito, admitiu-se que o lançamento do efluente no corpo d'água seria de acordo com os padrões da Resolução CONAMA no357 de 2005, que estabelece o limite de emissão de $20 \mathrm{mg} / \mathrm{L}$ para nitrogênio amoniacal.

A vazão de lançamento foi considerada igual a $0,6 \mathrm{~m}^{3} \mathrm{~s}^{-1}$. Este valor está disponível no website do empreendedor, o Serviço Autônomo de Água Esgoto de São Carlos (SAAE, www.saaesaocarlos.com.br).

As figuras a seguir mostram as concentrações de nitrogênio amoniacal, nitrito e nitrato ao longo do rio, simuladas pelo modelo QUAL-2E considerando a implantação da ETE e também o perfil do rio simulado para o dia 08 de Julho de 2008 sem a ETE.

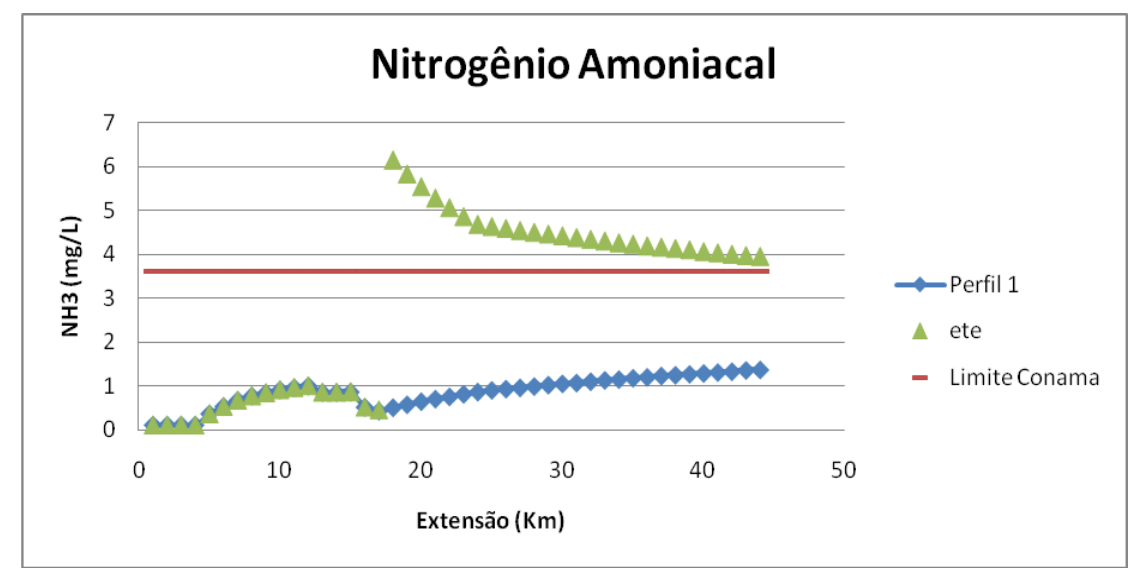

Figura 7 - Simulação - concentração de nitrogênio amoniacal após a implantação da ETE, o perfil 1 sem a implantação e o limite da resolução CONAMA 357 de 2005. 

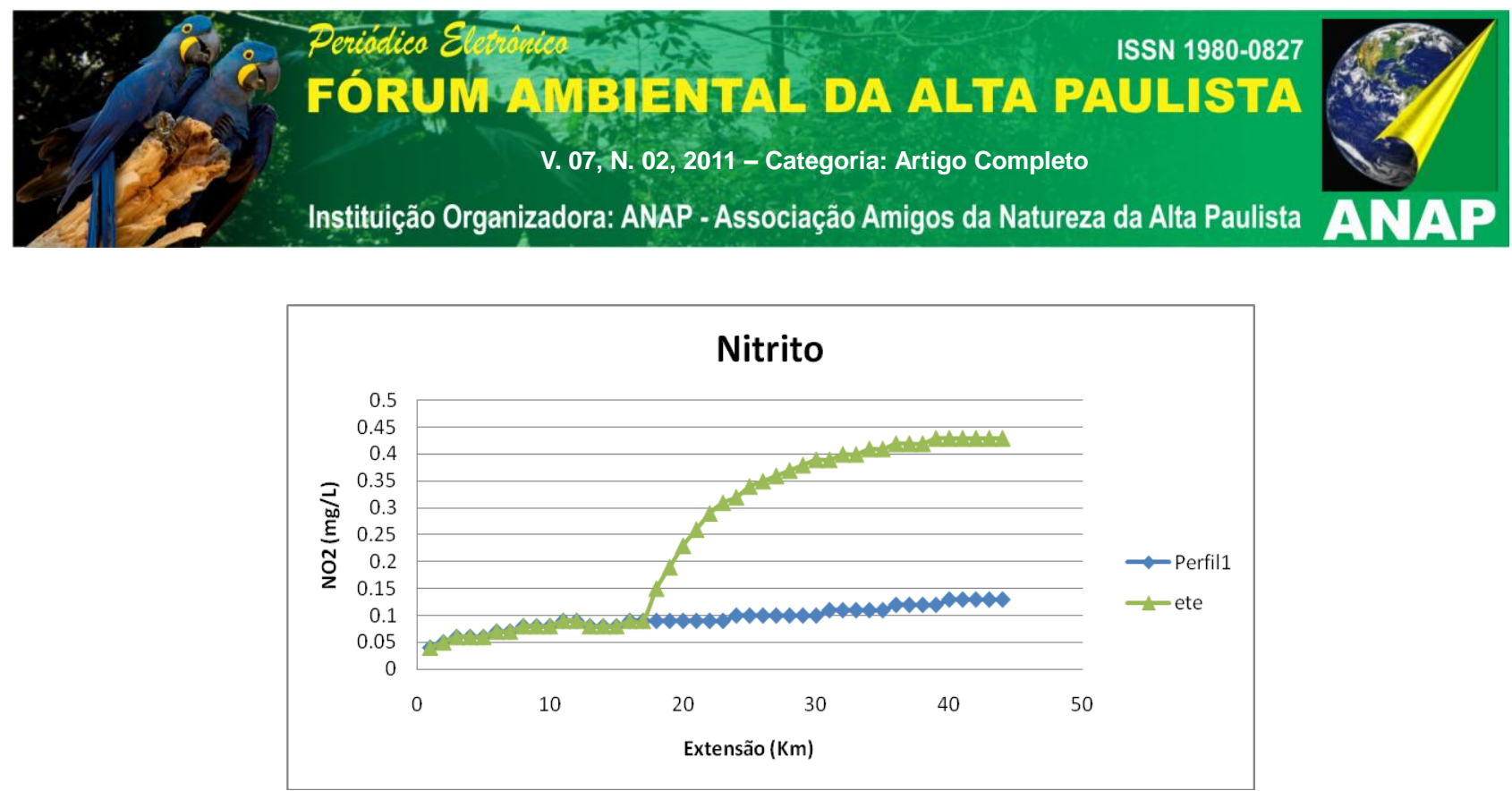

Figura 8 - Simulação - concentração de nitrito após a implantação da ETE e o perfil 1 sem a implantação.

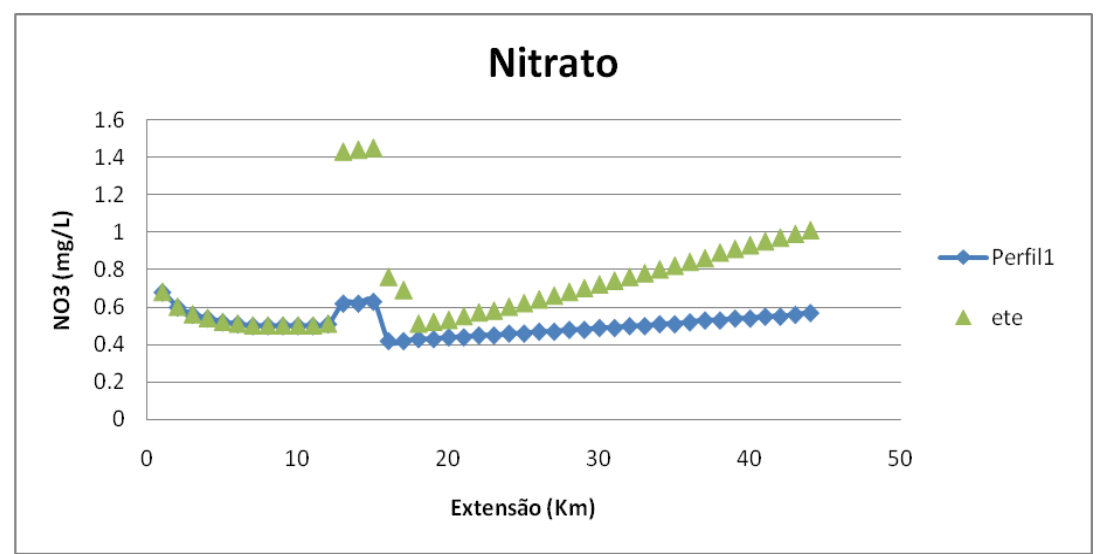

Figura 9 - Simulação - concentração de nitrato após a implantação da ETE e o perfil 1 sem a implantação.

Pelas figuras 7, 8 e 9 observa-se que o rio Monjolinho sentirá a influência da ETE de São Carlos quanto à concentração de nitrogênio. Nota-se que a concentração de nitrogênio amoniacal extrapola os limites da resolução CONAMA 357 que limita a concentração desse parâmetro de 3,7 em rios classe 1 e 2 . O nitrato e nitrito não ultrapassam o limite da resolução apesar de terem suas concentrações elevadas devido ao lançamento da ETE. O limite do nitrato é de $10 \mathrm{mg} / \mathrm{L}$ e do Nitrito é $1 \mathrm{mg} / \mathrm{L}$.

Observa-se também, quanto aos processos de conversão da amônia, que enquanto a concentração de nitrogênio amoniacal decresce a partir do ponto de lançamento, a concentração de nitrato e nitrito tende a aumentar, já que o N-Amoniacal é levado a Nitrito pelo processo de nitrificação e posteriormente o Nitrito é oxidado a Nitrato, pelo processo de nitratação.

Nota-se também uma estabilidade na concentração de nitrogênio amoniacal próximo ao limite da resolução CONAMA e a concentração de nitrito em $0,45 \mathrm{mg} / \mathrm{L}$. Já a concentração de nitrato não se estabiliza dentro do perfil, o que mostra que o processo de nitratação ainda está ocorrendo após o fim do trecho estudado. 


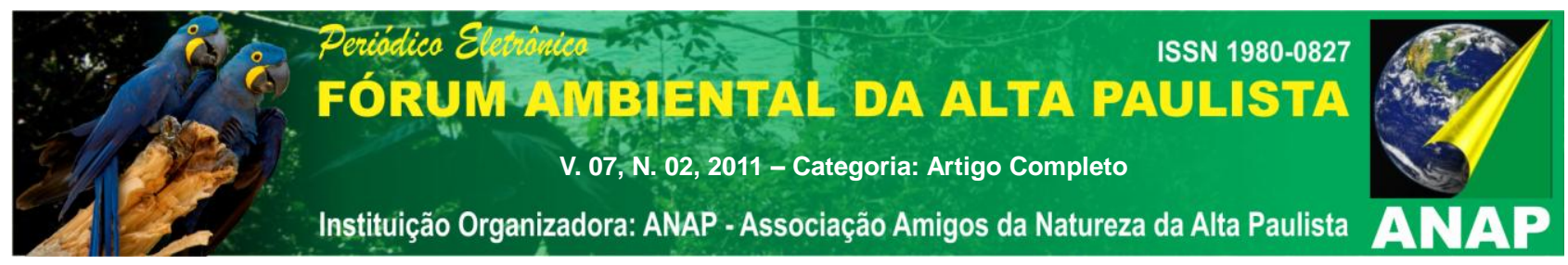

\section{CONCLUSÃO}

Ao utilizar modelos matemáticos para estudos sobre qualidade da água, deve-se dar imensa importância para a fase de calibração do modelo, pois este vai ser o momento determinante para o sucesso ou não das simulações. Deve-se levar em consideração a complexidade existente em se trabalhar com variáveis e coeficientes que muitas vezes são estimados, sendo que estes têm que se adequar à realidade de cada estudo específico.

Ao se trabalhar com qualidade da água deve-se considerar que os corpos d'água estão inseridos em sistemas complexos maiores, como as cidades e as bacias hidrográficas. Esses sistemas sofrem alterações ao longo do tempo por meio de processos antrópicos, como a urbanização, a ocupação do campo por atividades agropecuárias, entre outros. Todo esse contexto influencia diretamente na dinâmica dos corpos d'água e, portanto deve ser estudado juntamente com os parâmetros de qualidade da água.

Com as simulações feitas pode-se constatar que o nitrogênio e o fósforo são bons parâmetros indicadores do nível de poluição do corpo d'água, pois foram capazes de identificar cargas pontuais irregulares no perfil do rio e o seu estágio de poluição.

Constatou-se que o rio Monjolinho apesar de ter sofrido uma pequena melhora em sua qualidade, comparando os valores obtidos por Barreto (1999) com a campanha realizada nesse trabalho, ainda sofre sérios problemas de poluição, devido principalmente a descargas difusas e lançamentos de esgoto irregulares, que são conseqüências do forte processo de urbanização da Bacia Hidrográfica, sendo o pior trecho o que se inicia a montante da confluência do Tijuco preto, seguindo adiante com o Gregório até a montante da usina hidrelétrica.

As simulações feitas considerando a implantação da ETE de São Carlos, apesar de não trazerem dados reais da característica do efluente a ser lançado, pode ser analisada como um alerta para a concentração de nitrogênio no efluente, pois os estudos mostraram que mesmo dentro dos padrões estabelecidos pelo CONAMA sobre emissão de efluentes (devido às particularidades do rio), o limite de nitrogênio amoniacal pode ser ultrapassado, quando somado às cargas já existentes.

Vale ainda ressaltar a importância de estudos que levem em consideração as concentrações de nutrientes nos corpos d'água concomitantemente com os parâmetros relacionados à concentração de matéria orgânica, já que os rios são sistemas complexos onde as variáveis estão relacionadas.

Por fim, considera-se o modelo QUAL2E uma ferramenta útil na simulação de qualidade da água, sendo esse um mecanismo que ao ser aplicado levando em conta as particularidades de cada sistema, se mostra muito útil para o entendimento dos processos bioquímicos de conversão do nitrogênio e fósforo, podendo ser decisivo para tomadas de decisão de uma bacia hidrográfica, por apresentar os perfis do rio considerando diferentes possibilidades de descargas e lançamento de efluentes. 


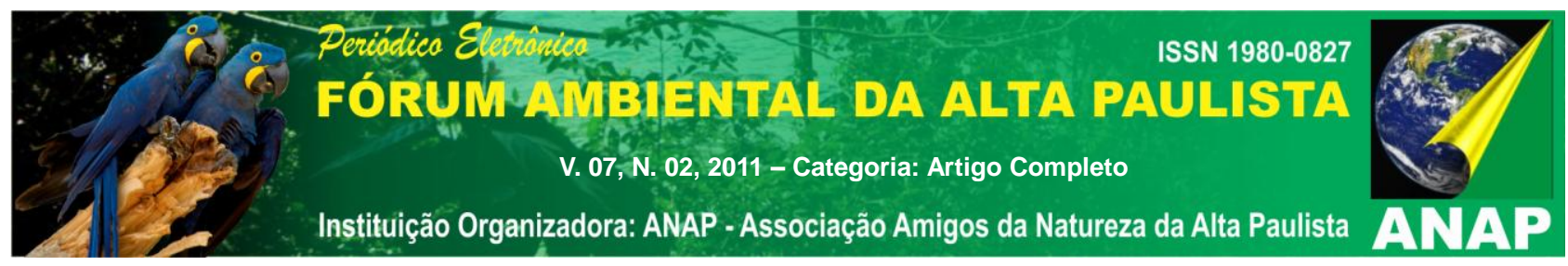

\section{BIBLIOGRAFIA}

BARRETTO, A. DOS S. Estudo da distribuição de metais em ambiente lótico, com ênfase na assimilação pelas comunidades biológicas e na sua quantificação no sedimento e água. EESC/USP - São Carlos - SP, 1999.

BRASIL. Resolução CONAMA n. 20, de 18 de junho de 1986. Diário Oficial [da] República Federativa do Brasil, Brasília - DF, 1986.

BRASIL. Resolução CONAMA n. 357, DE 17 de março de 2005. Diário Oficial [da] República Federativa do Brasil, Brasília - DF, 2005.

CETESB. Relatório de Qualidade das Águas Interiores do Estado de São Paulo: relatório anual - 2005. São Paulo - SP, 2006.

FAGUNDES, Vinicius B. Uso do Modelo QUAL2E no estudo da qualidade da água e capacidade de autodepuração do Rio Araguari - AP. Goiânia - GO, 2006.

FISCHER, E.G. Determinação do grau de contaminação do Ribeirão Feijão através de levantamento de dados e modelo matemático de qualidade da água. EESC/USP - São Carlos, São Paulo - SP, 1995.

JAMES, A. Mathematical Models in Water Pollution Control. Wiley, Nova lorque - EUA, 1978.

LIMA, E.B.N.R. Modelagem Integrada para Gestão da Qualidade da Água na Bacia do Rio Cuiabá. COPPE/UFRJ, Rio de Janeiro - RJ, 2001.

LOUCKS, D. Serie in water resources and Enironmental Engineering, McGraw Hill, Nova Iorque - EUA, 1981.

OPPA, L. F. Utilização de modelo matemático de qualidade da água para análise de alternativas de enquadramento do rio Vacacaí Mirim. UFSM, Santa Maria - RS, 2007.

PALMIERI, V. Calibração do modelo QUAL2E para o rio Corumbatí (SP). PUC -Rio de Janeiro RJ, 2004.

RODRIGUES, R. B. Sistema de suporte a decisão proposta para a gestão qualiquantitativados processos de outorga e cobrança pelo uso da água. USP, São Paulo-SP, 2005.

SÉ, J.A.S. O Rio do Monjolinho e sua bacia hidrográfica como integradores de sistemas ecológico. EESC/USP - São Carlos - SP, 1992.

SPERLING, M. V. Introdução a qualidade das águas e ao tratamento de esgotos. UFMG, Belo Horizonte - MG, 2005.

TUCCI, C.E.M. Modelos hidrológicos. UFRGS, Porto Alegre-RS, 1998.

SAAE Serviço Autônomo de Água e Esgoto de São Carlos. São Carlos-SP, 2008. Disponível em <http://www.saaesaocarlos.com.br>. Acesso em 20 de julho de 2008. 